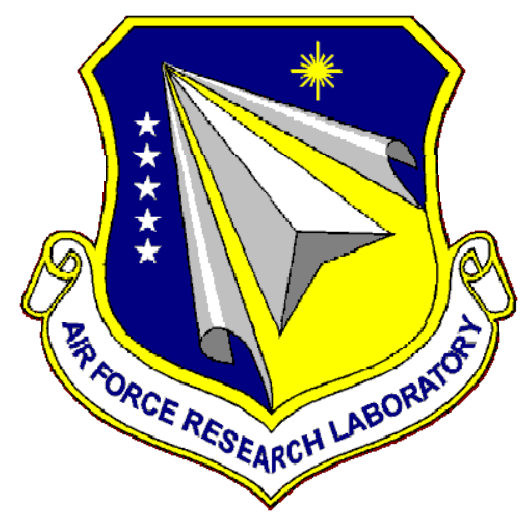

\title{
AFRL-RH-WP-TP-2014-0038
}

\section{SIGNATURE TRACKING FOR OPTIMIZED NUTRITION AND TRAINING (STRONG)}

Joshua Hagen

Human Signatures Branch

AUGUST 2014

Interim Report

Distribution A: Approved for public release; distribution is unlimited.

AIR FORCE RESEARCH LABORATORY

$7_{11}^{\text {TH }}$ HUMAN PERFORMANCE WING, HUMAN EFFECTIVENESS DIRECTORATE

WRIGHT-PATTERSON AIR FORCE BASE, OH 45433

AIR FORCE MATERIEL COMMAND

UNITED STATES AIR FORCE

\section{STINFO COPY}




\section{NOTICE AND SIGNATURE PAGE}

Using Government drawings, specifications, or other data included in this document for any purpose other than Government procurement does not in any way obligate the U.S. Government. The fact that the Government formulated or supplied the drawings, specifications, or other data does not license the holder or any other person or corporation; or convey any rights or permission to manufacture, use, or sell any patented invention that may relate to them.

This report was cleared for public release by the $88^{\text {th }}$ Air Base Wing Public Affairs Office and is available to the general public, including foreign nationals. Copies may be obtained from the Defense Technical Information Center (DTIC) (http://www.dtic.mil).

AFRL-RH-WP-TP-2014-0038 HAS BEEN REVIEWED AND IS APPROVED FOR PUBLICATION IN ACCORDANCE WITH ASSIGNED DISTRIBUTION STATEMENT.

//signature//

JOSHUA HAGEN

Work Unit Manager

Human Signature Branch //signature///

LOUISE CARTER, PhD

Chief, Human-Centered ISR Division

Human Effectiveness Directorate

$711^{\text {th }}$ Human Performance Wing

Air Force Research Laboratory

This report is published in the interest of scientific and technical information exchange, and its publication does not constitute the Government's approval or disapproval of its ideas or findings. 


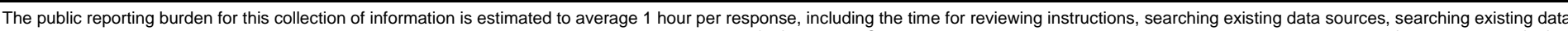

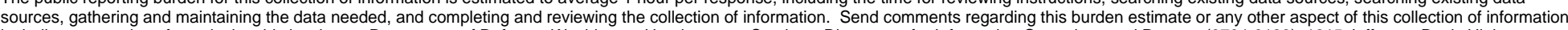

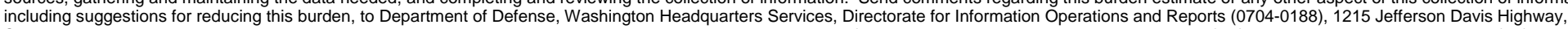

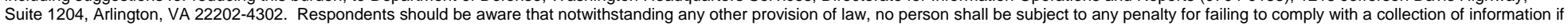
it does not display a currently valid OMB control number. PLEASE DO NOT RETURN YOUR FORM TO THE ABOVE ADDRESS
1. REPORT DATE (DD-MM-YY) 200814 2. REPORT TYPE Interim

\section{TITLE AND SUBTITLE}

Signature TRacking for Optimized Nutrition and TraininG (STRONG)

\section{AUTHOR(S)}

Joshua Hagen

\section{DATES COVERED (From - To)} 10/01/12- 06/30/2014

5a. CONTRACT NUMBER In-House

5b. GRANT NUMBER

5c. PROGRAM ELEMENT NUMBER 62202F

5d. PROJECT NUMBER

5e. TASK NUMBER

5f. WORK UNIT NUMBER (H089) 7184C003

7. PERFORMING ORGANIZATION NAME(S) AND ADDRESS(ES)

8. PERFORMING ORGANIZATION REPORT NUMBER

10. SPONSORING/MONITORING AGENCY ACRONYM(S) $711 \mathrm{HPW} / \mathrm{RHXB}$

11. SPONSORING/MONITORING AGENCY REPORT NUMBER(S)

AFRL-RH-WP-TP-2014-0038

\section{Human-Centered ISR Division}

Human Signatures Branch Wright-Patterson Air Force Base, OH 45433

\section{DISTRIBUTION/AVAILABILITY STATEMENT}

Distribution A: Approved for public release; distribution is unlimited.

13. SUPPLEMENTARY NOTES 88ABW-2014-3940; Cleared 22 Aug 2014

14. ABSTRACT

The STRONG Team describes a holistic approach to human performance augmentation led by multiple researchers at AFRL. Research areas include Physical Training, Nutrition/Supplementation, Signatures, and Tracking.

\section{SUBJECT TERMS}

Human performance, nutrition, supplementation, signatures, wearable electronics, flexible electronics

\begin{tabular}{|c|c|c|c|c|c|}
\hline \multicolumn{3}{|c|}{ 16. SECURITY CLASSIFICATION OF: } & \multirow{2}{*}{$\begin{array}{l}\text { 17. LIMITATION } \\
\text { OF ABSTRACT: } \\
\text { SAR }\end{array}$} & \multirow{2}{*}{$\begin{array}{l}\text { 18. NUMBER OF } \\
\text { PAGES } \\
7\end{array}$} & \multirow{2}{*}{$\begin{array}{l}\text { 19a. NAME OF RESPONSIBLE PERSON (Monitor) } \\
\text { Josh Hagen } \\
\text { 19b. TELEPHONE NUMBER (Include Area Code) } \\
\text { N/A }\end{array}$} \\
\hline $\begin{array}{c}\text { a. REPORT } \\
U\end{array}$ & $\begin{array}{c}\text { b. ABSTRACT } \\
U\end{array}$ & $\begin{array}{c}\text { c. THIS PAGE } \\
\text { U }\end{array}$ & & & \\
\hline
\end{tabular}


THIS PAGE LEFT BLANK INTENTIONALLY. 


\section{Signature TRacking for Optimized Nutrition and Training (STRONG) VISION STATEMENT}

Measurement and assessment of cognitive and physical performance biosignatures to generate novel augmentation strategies through innovative physical training, unique supplementation, and state-of-the-art technologies for optimized performance.

\section{TEAM DESCRIPTION}

Air Force Research Laboratory: $711^{\text {th }}$ Human Performance Wing

"The game changer for the AF is personalized health and performance. It optimizes individuals' health, wellness and performance through the networking of nano, 'omics,' mobile, and sensing technologies, provides an unprecedented level of real-time continuous feedback. Opportunities for performance augmentation include continuous performance feedback for self-improvement and individualized training regimens in the near- and mid-terms, respectively.” Global Horizons, 2013.

The STRONG Team is an organized teaming of researchers and projects in the $711^{\text {th }}$ Human Performance Wing directly addressing the needs associated with one of the game changers defined by Global Horizons: Personalized Health and Performance. Combining the unique research efforts of Physical Training, Nutrition and Supplementation, Biometric/Biomarker Signatures, and Sensor Development into one team allows for a holistic approach to augmenting the performance of Airmen.

Overall Team Info POC: joshua.hagen.1@us.af.mil

“What can be measured, can be managed” (Drucker).

Imagine...you wake up on Monday morning and put on a new band-aid sized electronic sensor as you start your week. Your smartphone advises you on what to have for breakfast, along with supplements to prep you for your morning PT session. You head to the gym, where your Android training partner has a workout planned built on your predefined personal and missionbased physical goals. Success of the workout is not based solely on completing a certain number of tasks, but reaching a total workload centered on measurements from your band-aid where heart-rate, respiration rate and movement are measured. Advanced metrics like electrolyte and lactate values are quantified from your sweat via the electronic band-aid, allowing your smartphone to advise you on a hydration and nutrition strategy both during and post-workout. These electrolyte and lactate levels are based on your personal biochemistry, which has been mapped based on months to years of previous data. Long term physical goals are assessed by measured periodic metrics such as VO2 Max and body composition scanning, and nutrition and training strategies are altered directly by your Android training partner. New advanced workout techniques, such as kettle bell or agility training are sent to your smartphone based on new research validating the most effective training routines, as it pertains to your personal and mission-related physical goals. As you go through the rest of your day, you are guided on nutrition and supplementation to boost your physical and cognitive effectiveness. Your sleep patterns are tracked to optimize your daily recovery. All of these technologies, and more, are being developed within the STRONG Team to address the enormous potential of Personalized Health and Performance in the Air Force. 


\section{Training}

Military training in elite warfighters (e.g., U.S. Army Rangers, Navy SEALs, and U.S. Air Force Battlefield Airmen) is challenging and requires mental and physical capabilities that are akin to that of professional athletes. However, unlike professional athletes the competitive arena is the battlefield, with winning and losing replaced by either life or death. The rigors of both physical training and prolonged deployments without adequate rest and food intake can compromise performance. Therefore, one of the primary missions of the $711^{\text {th }}$ Human Performance Wing is to conduct research on physical training regimens and technologies that enhance performance of special operators as well as non-traditional training modalities that may reduce musculoskeletal injuries both during training and in the field. Our research team's efforts are focused on the application of advanced physical training methods used by elite athletes to improve fitness in Special Operators; such as functional weight training, kettlebell training, agility and reactiontime interventions, and Military Occupational Specialty (MOS) injury prevention exercises. We also explore operational stressors (e.g., negative energy balance, high energy expenditure, sleep deprivation, environmental extremes, heavy load carriage, etc) associated with rigorous training and sustained operations and their negative impacts on hormonal levels, lean muscle mass, and field performance. Our team investigates the usage of simple field tests to predict performance and indicate overtraining in Special Operators during training and prior to mission deployments.

Our team also specializes in cooling technologies that mitigate heat stress. In addition to impairing operational effectiveness, heat illness results in considerable morbidity during recruit training, and heat stroke remains a common cause of preventable nontraumatic exertional death in the U.S. military. Therefore, our team continues to develop and test various cooling products to determine their effectiveness in mitigating heat stress. Our team recently designed a cooling garment for Russell Athletic made from technical, breathable material that reduces core temperature during heavy exercise.

\section{Training POCs: molly.wade@us.af.mil /reginald.ohara@us.af.mil}

\section{Nutrition and Supplementation}

Nutrition and Supplementation is a relatively new area of research within the Air Force. As many know, the Army is the leader of nutritional research in the armed services, however much of their research is focused on MRE components, the amount of calories needed to complete a job, and which foods give the most 'bang for the buck'. The STRONG team offers a novel component to this research in that we focus on how nutritional diets and supplements can influence both physical and cognitive performance. It has been shown through previous research efforts that military performance can be negatively affected by physical, psychological, or environmental stress, leading to degraded cognitive processes (memory, attention) which could impair skill acquisition and performance during intensive military training. Thus, augmentation strategies, such as the use of supplements like dehydroepiandrosterone (DHEA) may improve stress resilience and promote cognitive readiness. Future research efforts will observe the effects of DHEA supplementation during combat controller (CCT) training to determine if implementing this nutritional intervention can improve learning and cognitive performance. A different and novel approach the STRONG team is taking involves a nutraceutical interventions, leveraging research within academia and industry. The STRONG team is currently building a collaborative relationship with the Beckman Institute at the University of Illinois to explore the benefit of nutraceutical intervention on both physical and cognitive performance. The STRONG 
team is also uniquely equipped to perform animal model studies which investigate nutritional supplementation and the underlying biological/physiological mechanisms these augmentation strategies impose. The above research efforts are a small beginning to a much larger research area within the $711^{\text {th }} \mathrm{HPW}$. Along with performing these studies, the STRONG team will also perform a much-needed investigation into current nutrition and supplement technology by reaching out to leaders in the DoD, Industry and private sectors for a better understanding of current issues and future initiatives in these areas. This will help to ensure that the work done within the STRONG team is at the cutting edge of the nutrition/supplementation arena. This research augments the Training portion of the team and is influenced by results from the Signatures section.

\section{Nutrition and Supplementation POC: Erica.Johnson.7@us.af.mil}

\section{Signatures}

The Applied Neuroscience Branch (711 HPW/RHCP) in AFRL has been evaluating known biomarker patterns as well as identifying novel biomarker signatures of performance optimization and stress resilience. Specifically, this knowledge allows for the identification of proper resource expenditure during stressful events that may include physical exhaustion or lapses in attention. This information also allows for the identification of poor vs. successful cognitive functioning following the elicitation of a stressful event. In addition, the study designs and applications allow for the comparison of various forms of biofluid expression in order to leverage state-of-the-art biomarker technology. The Signatures section of this team assesses various biomarkers and biometrics to inform what should be sensed for Tracking and augmented through Nutrition, Supplementation and Training.

Signatures POC: regina.shia@us.af.mil

\section{Tracking}

The Human Centric Sensor Systems program (711 HPW/RHXB) in AFRL develops wearable sensor technologies for complete physiological monitoring. These technologies are split into two areas, 1) vital signs and 2) biofluids. Development of vital sign monitoring devices is highly collaborative with industry and academia, and focused on lightweight, adhesive, wireless, and disposable attributes. Key vital sign devices being developed include heart rate, respiration rate, pulse oximetry, single lead EKG, and motion measurements. These devices have multiple uses in the AF, including current projects for medical monitoring for Pararescue and En Route Care. In this program, they are being customized for measuring and assessing physical and cognitive performance. Wearable biomarker monitoring in biofluids is a novel technology being developed by AFRL. Non-invasive monitoring of biomarkers in sweat is being developed in a band-aid form factor for hydration (electrolyte), performance (lactate), and stress/fatigue (cortisol et. al). Vital sign and biomarker selection for device development is fed by the Signatures and Training groups.

Tracking POC: joshua.hagen.1@us.af.mil. 